\title{
Effect of the reaction of ammonia gas on the swelling of metallic iron and its oxides during nitriding processes
}

\author{
Oscar Dam G \\ ORCID: https://orcid.org/0000-0002-0594-6757 \\ UNEXPO,FellowIIMA,oscar.curmetals@gmail.com \\ Edo. Bolívar, Venezuela
}

\author{
Luis Azocar \\ ORCID: https://orcid.org/0000-0002-7683-4488 \\ UNEXPO. Puerto Ordaz \\ azocarluisalberto@hotmail.com \\ Edo. Bolívar, Venezuela
}

Received (15/04/21), Accepted (07/05/21)

\begin{abstract}
In order to study the relationship and effect of nitrogen gas in the reducing gases used in the reducibility tests of iron oxides, under isothermal conditions, a test scheme was executed using ammonia gas, such that its decomposition of the gas in the reactor produced a mixture of $\mathrm{H} 2$ and $\mathrm{N} 2$ gases. Furthermore, the addition of $6 \%$ $\mathrm{NH} 3$ in a $28 \% \mathrm{H} 2$ and $68 \% \mathrm{~N} 2$ gas stream was planned to obtain a gas composition of $70 \% \mathrm{~N} 2$ and $30 \% \mathrm{H} 2$. This would allow comparing the reducibility curves between both conditions, assuming that the possible difference between both conditions to compare the volume changes of the reduced samples. The difference to be studied will be based on the estimation and comparison of the rate of formation of metallic iron in the stages of reduction of Hematite / Magnetite / Wustite $(\mathrm{FeO})$, as well as the effects of nitrogen absorbed by the fresh metallic iron produced, or present. in iron catalysts to produce ammonia, from the reducing gas mixture, on the volume change of the samples. Likewise, the catastrophic volume changes caused by nitrogen are compared by comparing sources of this gas in solid carbonaceous reducers.
\end{abstract}

Keywords: Gaseous Reduction, Direct Reduced Iron, isothermal tests.

\section{Efecto de la reacción de gas de amoniaco sobre el hinchamiento de hierro metálico y sus óxidos durante procesos de nitruración}

Resumen: Con el objeto de estudiar la relación y efecto del gas nitrógeno en los gases reductores utilizados en los ensayos de reductibilidad de óxidos de hierro, en condiciones isotérmicas, se ejecutó un esquema de ensayos utilizando gas amoniaco, tal que su descomposición en el reactor produjera una mezcla de gases de H2 y N2. Además, se planifico la adición de $6 \%$ de NH3 en una corriente de gas $28 \%$ H2 y 68\% N2 para obtener una composición de gas de $70 \%$ N2 y $30 \%$ H2. Esto permitiría comparar las curvas de reductibilidad entre ambas condiciones, asumiendo que la posible diferencia entre ambas condiciones a comparar los cambios de volumen de las muestras reducidas. La diferencia a estudiar se basará en la estimación y comparación de la velocidad de formación de hierro metálico en las etapas de reducción de hematita/magnetita/wustita $(\mathrm{FeO})$, así como los efectos del nitrógeno absorbido por el hierro metálico fresco producido, o presente en catalizadores de hierro para producir amoniaco, a partir de la mezcla de gas reductor, sobre el cambio de volumen de las muestras. Así mismo se comparan los cambios catastróficos de volumen causados por el nitrógeno comparando fuentes de este gas en reductores carbonosos sólidos.

Palabras Clave: Campos Electromagnéticos, Líneas de transmisión, torres de transmisión. Reducción gaseosa, Hierro de reducción directa, ensayos isotérmicos. 


\section{I.INTRODUCTION}

To study the relationship and effect of nitrogen gas in the reducing gases used in the iron oxide reducibility tests, under isothermal conditions, a test scheme was executed using ammonia gas, such that the decomposition of the gas in the reactor would produce a gas of $15 \% \mathrm{H} 2$ and $25 \% \mathrm{~N} 2$. In addition, the addition of $6 \% \mathrm{NH} 3$ in an $\mathrm{H} 2$ and $\mathrm{N} 2$ gas stream was planned to obtain a gas composition of $70 \% \mathrm{~N} 2$ and $30 \% \mathrm{H} 2$ at a gas flow rate of 2 liters/ minute. The comparative study will be based on the estimation and comparison of the rate of metallic iron formation in the hematite/magnetite/wustite $(\mathrm{FeO})$ reduction stages, as well as the effects of the nitrogen absorbed by the metallic iron, to that produced in parallel during the reduction process, on the volume change of the samples. The volume changes caused by nitrogen are also compared by comparing sources of this gas in solid carbonaceous reductants.

\section{II.REDUCTIBILITY TESTS}

The reducibility tests were carried out in a stainless steel reactor [1], using samples of hematitic iron ore with a porosity of $3 \%$ and an iron content of $69.05 \%$ in weight with measures of a cube of dimensions $3 \times 3 \times 3 \mathrm{~mm}$ per side. On the other hand, the gases used were mixed to obtain compositions of $30 \% \mathrm{H} 2$ and $70 \% \mathrm{~N} 2$, and $28 \% \mathrm{H} 2$ and $68 \% \mathrm{~N} 2$, and $6 \% \mathrm{NH} 3$, with this last mixture when decomposed, the first composition would be obtained, but the adsorption and activation reactions of the hydrogen gas would be obviated to react with the oxygen in the reaction front for reduction, and generate $\mathrm{H} 2 \mathrm{O}$, and of the nitrogen to be absorbed by the metallic iron, since all the gaseous species are assumed as "nascent", that is in the form of $\mathrm{H}+2$ ions, $\mathrm{N}=2$ and metallic Fe formed from $\mathrm{Fe}=3$ ions with 4 tetrahedral vacancies passing to $\mathrm{Fe}=2$ and metallic $\mathrm{Fe}$, releasing 4 vacancies and the associated energy of between 1.98 and 2.52 Ev/Vacancy [2] Between 100 and $140{ }^{\circ} \mathrm{C}$, while Dam [1] estimated this value at $1.28 \mathrm{Ev} /$ Vacancy calculated at $25^{\circ} \mathrm{C}$. For the estimation of the chemical composition of the reduced oxide, it is estimated using the method deduced by Dam and Jeffes [3].

\section{III.RESULTS}

The reducibility curves of the cubic samples used under $100 \% \mathrm{NH} 3$ conditions and with the $6 \% \mathrm{NH} 3$ mixtures in $30 \% \mathrm{H} 2 / 70 \% \mathrm{~N} 2$ gas mixtures are shown in Figures 1 and 2. In this figure, it can be seen that the reducibility of the same mineral is faster with ammonia gas than with the $30 \%$ Hydrogen and $70 \%$ Nitrogen mixture, which is associated with the reduction of the activation step of the hydrogen molecule on the surface of the oxide to adsorb before chemically reacting with oxygen and then desorbing, since the adsorption of the NH3 molecule on the oxide surface, it decomposes into $\mathrm{H}=2$ ions ready to react with $\mathrm{O} / 2$ ions accelerating the reduction reaction. Both curves fitted by least-squares have R-squared correlation coefficients of 0.99 and 0.98 respectively.

$$
\% R=0,1629 t^{2}+6,8198 \mathrm{t}-0,2283 \quad\left(\mathrm{NH} 3,850{ }^{\circ} \mathrm{C}\right)
$$

$$
\% R=-0,1494 t^{2}+6,105 t-2,9935 \quad\left(30 \% H 2 / 70 \% N 2,900^{\circ} \mathrm{C}\right)
$$




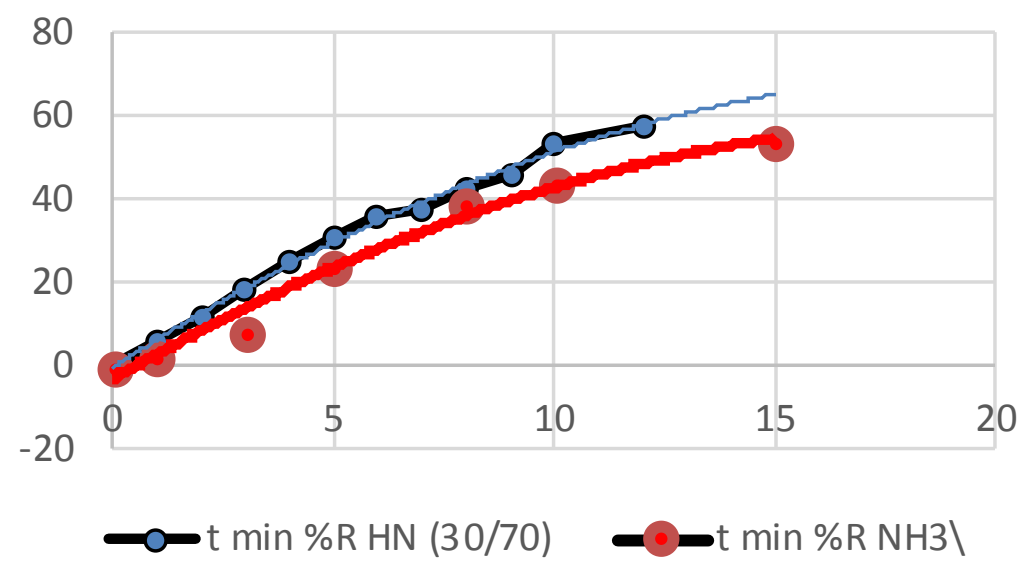

Fig. 1. Reduction curve \%Reduction (y-axis) versus time (x-axis, minutes). [1], upper curve Eq. 2, lower curve Eq. (1).

The determination of the formation of the chemical composition of the reduced product, regarding the evolution of iron formation, the model deduced by Dam and Jeffes [3] was used, obtaining the results shown in Figure 2. In this figure, it can be seen that the formation of metallic iron starts earlier than in an atmosphere of $30 \% \mathrm{H} 2$ and $70 \%$ Nitrogen, which corresponds to higher reducibility as shown in Figure I, in both curves a correlation coefficient R square of 0.99 was obtained for both mathematical expressions, as shown below.

$$
\% \text { Fe met }=0,3678 \mathrm{t}^{2}-0,8423 \mathrm{t} \quad(\mathrm{NH} 3,850 \sim \mathrm{C})
$$

$$
\% \text { Fe met }=0,3101 \mathrm{t}^{2}-1,0057 \mathrm{t}-0,2189(30 \% \mathrm{H} 2 / 70 \% \mathrm{~N} 2,900 \sim \mathrm{C})
$$

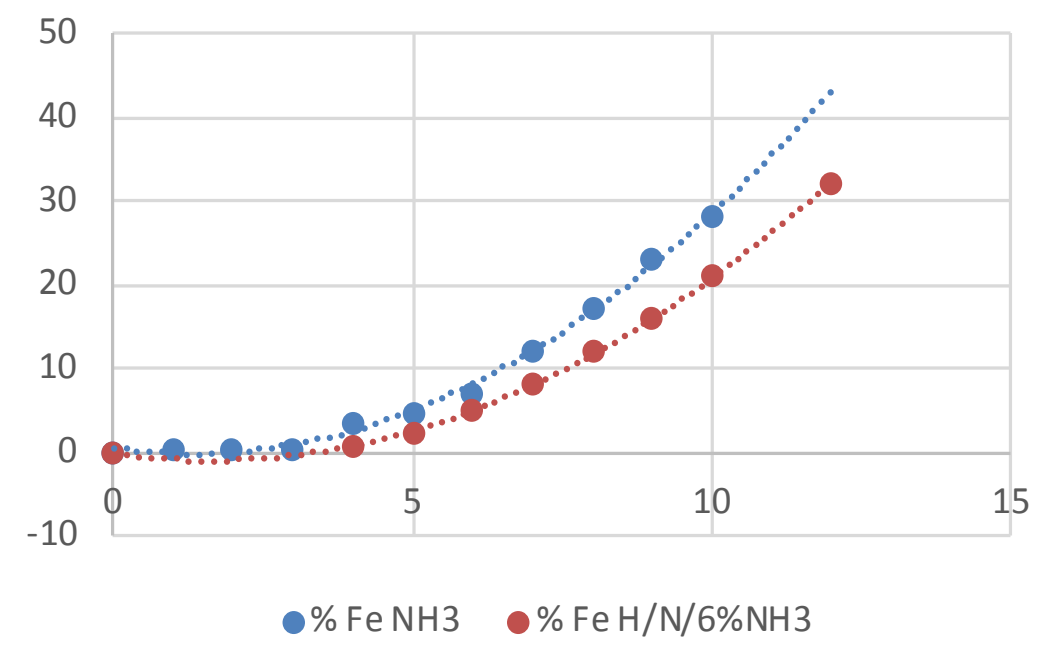

Fig. 2. Metallic iron formation (\% Fe met, $y$-axis) versus reduction time ( $t$ min, $x$-axis, min). [1].

When the metallic iron formation values are expressed as metallization rate (dFe met/dt), Figure 3 is obtained, in which it can be observed that the rate of formation of this metallic iron in the early stages of the reduction pro- 
cess from the transformation of the magnetite/wustite $(\mathrm{FeO})$ phases to form metallic Fe.

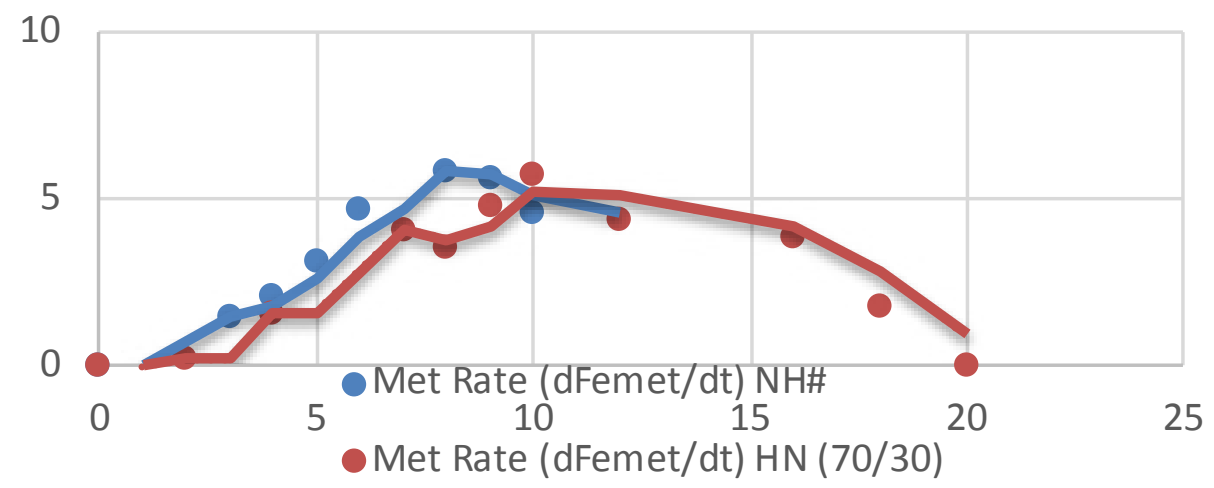

Fig. 3. Metallic Fe formation rate (y-axis) and reduction time (x-axis, min). (Source. Author's own) [1].

This expression of this rapidity, with an intermediate value between these gaseous mixtures and others with higher reducing power and temperatures, is generated by an energy release mechanism to dissociate the NH3 molecules and provide the energy necessary to form the activated hydrogen and nitrogen molecules on the surface of the solid. This energy is obtained from the release of a cluster of vacancies associated with $\mathrm{Fe}+3$ ions passing to $\mathrm{Fe}+2$ and subsequently to metallic $\mathrm{Fe}$. For the schematic representation of the reduction reaction involving the energy per vacancy between $1.28 \mathrm{eV}$ [1] and between 1.98 and $2.25 \mathrm{eV}$ [2] and the crystalline effects of the species involved, this can be seen in Figure V $[2,4]$.
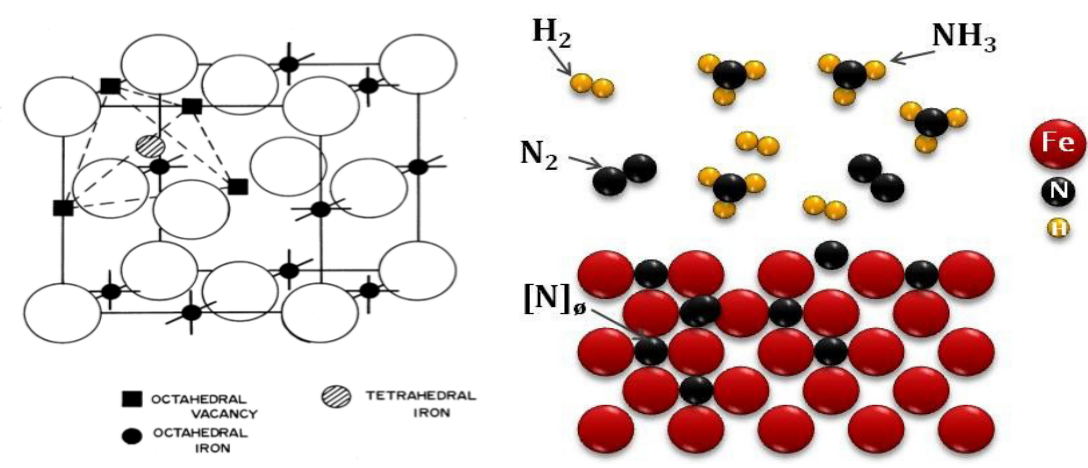

Fig. 4. Schematic of the interaction of NH3 molecules on the reaction surface of the oxide to be reduced and the vacancies and defects of iron oxides $[2,4]$.

\section{IV.EFFECT OF REDUCING GASES ON VOLUME CHANGE}

The effect of gases and especially nitrogen gas on the volume changes of iron oxides during reduction has been reported by Dam [1] referred by El Geassy [5], in this paper, we present the analysis of the data reported by Dam as the average maximum values of the volume change values of the samples subjected to reduction with mixtures of $30 \% \mathrm{H} 2$ and $70 \% \mathrm{~N} 2$. These values are compared with the values of dissolved nitrogen in iron, represented in the unstable Fe-N phase diagram, whose values are presented in Table 1. In Table I, the two values are represented for the temperature 900 degrees Celsius, since it is at this temperature that the allotropic change of alpha to gamma iron occurs and the measured volume change of experiments expressed in 1/10000, in favor of plotting on visible scales. 
Table 1. Variations of \% $\mathbf{N}$ dissolved in iron and volume of the samples (Author's source) [1].

\begin{tabular}{|l|c|c|c|c|c|c|c|}
\hline $\mathbf{T}^{\circ} \mathbf{C}$ & 700 & 800 & 850 & $900 \mathrm{Fe} \alpha$ & $900 \mathrm{Fe} \gamma$ & 950 & 1000 \\
\hline$\%[\mathbf{N}]$ & 0,0025 & 0,0033 & 0,0040 & 0,0053 & 0,0063 & 0,0256 & 0,0025 \\
\hline$\Delta$ Vol \% x 10E-4 & 0,0025 & 0,0028 & 0,0032 & 0,0034 & 0,0075 & 0,0060 & 0,0044 \\
\hline
\end{tabular}

The graphical representation of these values shows a very clear and noticeable trend correlation. It should be noted that the values of the percentage change in volume are divided by 1000 for graphical representation purposes

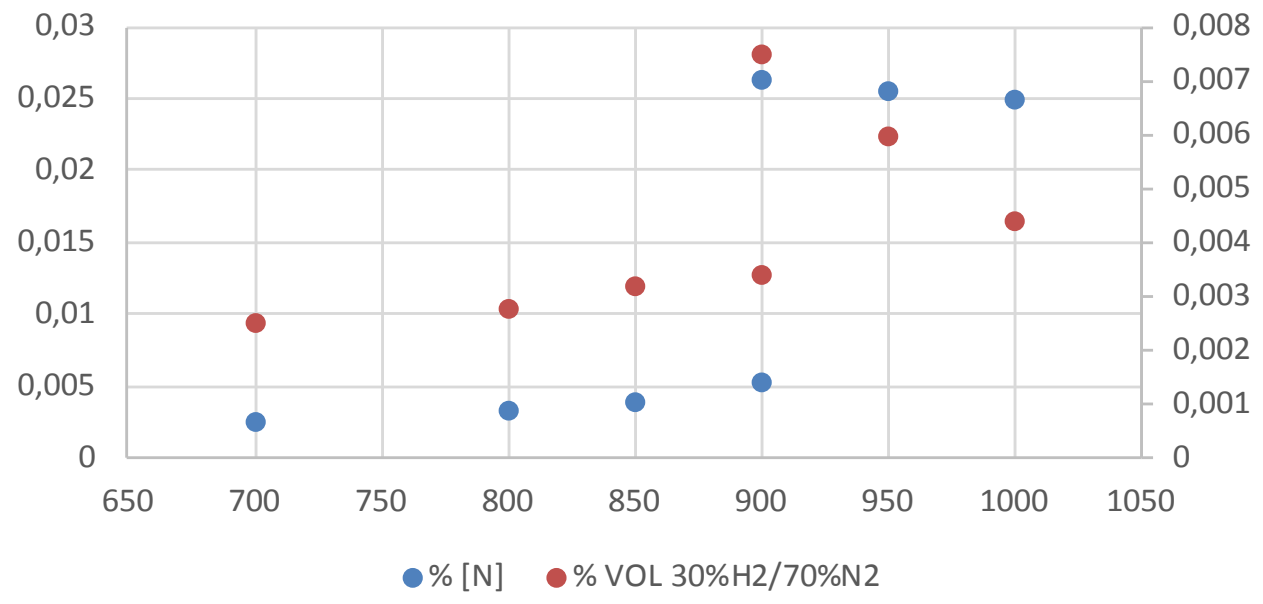

Fig. 5. Relationship between reduction temperature (x-axis) and Nitrogen content (\% y, left) and volume increase $(\% / 10000)$ (y-axis, right) (Author's source).

Since the absorption of nitrogen in iron causes distortions in the crystalline structure of both allotropic forms of iron considered in the temperature range studied and since the FeN stability diagram indicates that, upon cooling the samples, the desorption of nitrogen in the molecular form will occur, the system must supply necessary and equivalent activation energy of between 51 to $58 \mathrm{Kcal} / \mathrm{mol}$. This energy is equivalent to the binding energy of the FeN nitride [10] and whose effect has not been considered as mechanical stress involved in the volume changes considered.

\section{A.Origin of the nitrogen element of solid reductants.}

Since, in this comparative study, nitrogen has been mentioned as a component in a gaseous mixture, it is pertinent to review the origin of this element in other materials, such as solid carbonaceous reductants like coal, coke, and petroleum coke, under the condition of not competing with other sources of oxygen, that is, that the reduction process is not carried out in air atmospheres.

The nitrogen content in the coals is in the form of compounds of the $\mathrm{H}=\mathrm{N}=\mathrm{C}$ type so that the nitrogen content, although low to exert an appreciable effect on the studied phenomenon of abnormal swelling of the volume of the oxides present, must break the respective bonds to subsequently participate in the reduction reactions that include activation and adsorption states and then be absorbed into the iron produced. Therefore, it is to be expected that this effect will not occur. As a reference and to evidence this opinion, a comparison of reduction works carried out in India with local coals is made [6,7]. The reported values of the volume changes of the iron oxides used are compared with those of the experiences with $\mathrm{NH} 3$ gas reduction and $30 \% \mathrm{H} 2=70 \% \mathrm{~N} 2$ mixtures, as mentioned above. The comparison is presented graphically in Figure VI, where it can be seen that the compared values of the reduction experiments with Indian coals are very similar to the values reported for normal swelling, that is, up to the range of $30 \%$. 


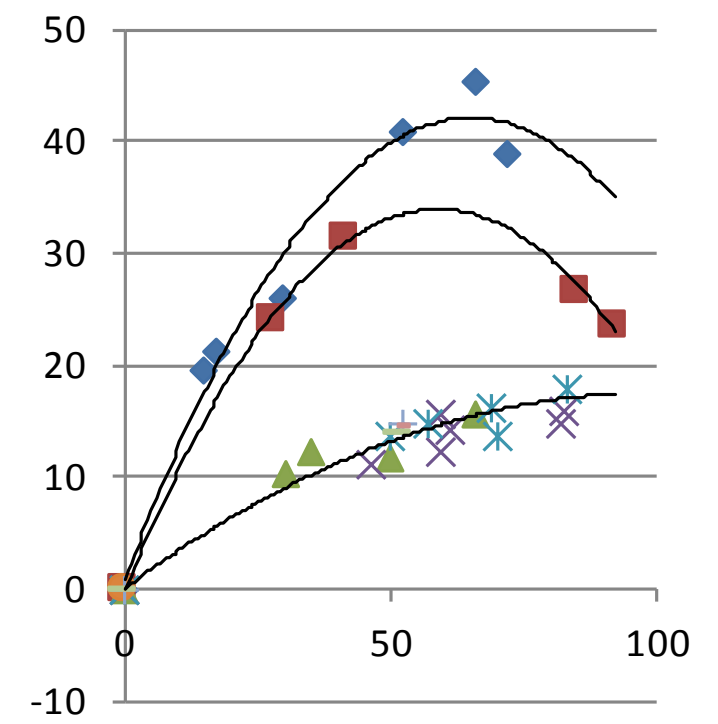

$\%$ VNH3 800

$\%$ VNH3 900

$\triangle \%$ V Agarwal 820

$\times \%$ Agarwal

870

* \% V Agarwal

920

Fig. 6. Comparison of swelling values of iron oxides reduced with NH3 and carbon ( $\Delta$ Vol $\%$, y-axis) as a function of the percentage of Reduction (\%R, $\mathrm{x}$-axis) at different temperatures in the range of 800 to 920

${ }^{\circ}$ C. (Source: Authors)

The curves in Figure 6 are mathematically represented as

$$
\begin{array}{ll}
\Delta \operatorname{Vol}(\%)=-0,0098 \% R^{2}+1,2676 \% R+0,8953 & \left(R^{2}=0,973\right) \\
\Delta \operatorname{Vol}(\%)=-0,0017 \% R^{2}+0,3489 \% R+0,0873 & \left(R^{2}=0,9698\right)
\end{array}
$$

The differences are basically seen in the coefficients of the quadratic expression, in a ratio of 5 to 1 or greater.

\section{B. Nitrogen absorption during the reduction process.}

Nitrogen absorption has been widely studied in the nitriding processes of steels, at $600{ }^{\circ} \mathrm{C}$, contents of $0.1 \%$ in weight have been reported [11\} and reporting a volume increase of between 10 and 20\% [12]. Other authors have reported contents of $0.0015 \%$ at $900{ }^{\circ} \mathrm{C}$, and 1 atmosphere of pressure [12). In the field of catalysis, nitrogen contents in catalysts of between $0.1 \%$ to $0.5 \%$ per gram of catalyst have been reported [13]. In the field of direct reduction of iron oxides, nitrogen contents of 0.005 to $0.01 \%$ in weight have been reported in reduced minerals in gaseous mixtures with 55 and $66 \%$ in weight nitrogen by volume [13]. For his part, Dam [1] reports the results of analyses for the remaining nitrogen content in samples reduced from $50 \mathrm{ppm}(0.005 \%$ in weight $)$ in samples with abnormal swelling greater than $40 \%$ according to Figure $\mathrm{V}$, using Micro-Kjendal techniques and vacuum melting technique for nitrogen determinations. These results are consistent with the curve in Figure VII, and whose mathematical expression is presented in Equation 7 as

$$
\%[N]=-5 E-05 \% R^{2}+0,0048 \% R-0,0989 \quad\left(R^{2}=0,9454\right)
$$




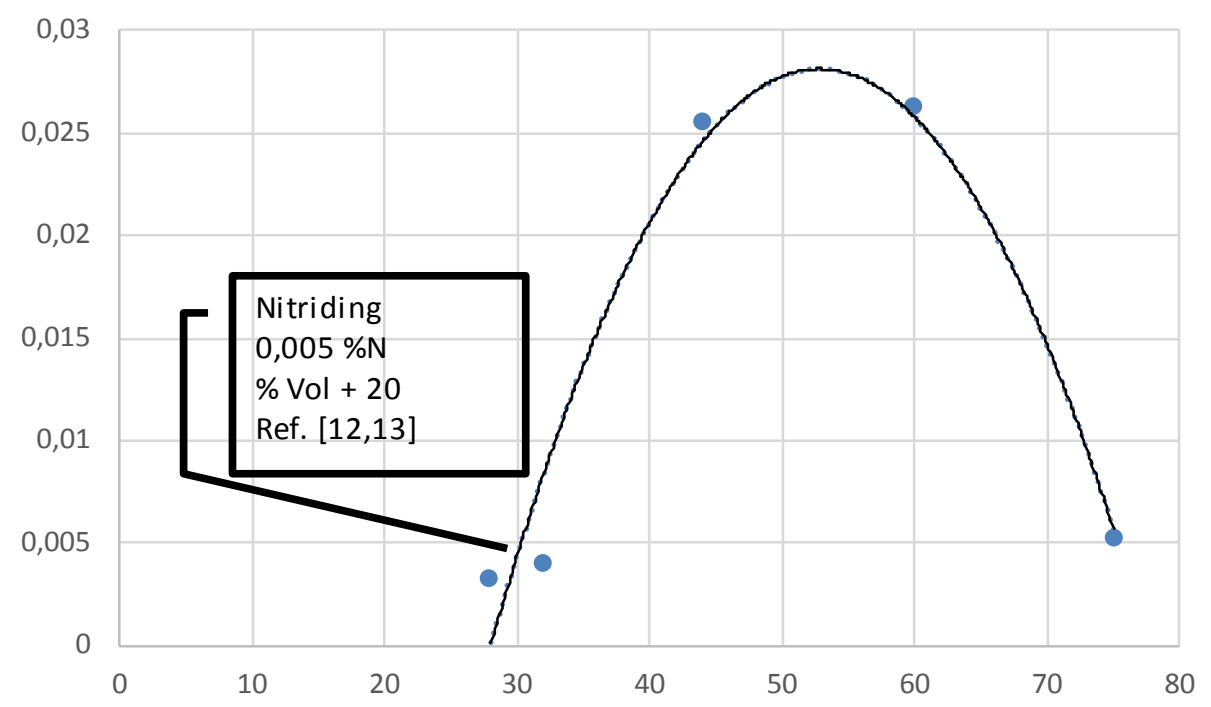

Fig. 7. Effect of dissolved nitrogen content (\%) in iron (y-axis) on volume increase (\%) (x-axis) during iron oxide reduction.(Source: Authors).

When applying the values of nitrogen content in iron by nitriding processes and nitrogen content in the samples reduced to room temperature, these values coincide with those estimated in the curve in Fig. 7. Note the similar trend of the curves shown in Fig. 6 and 7.

\section{V.CONCLUSIONS}

Comparison of the results of this paper leads to the following conclusions

1.The relationship between the mechanism of the swelling phenomenon of iron oxides with the mechanism of nitrogen absorption in fresh nascent iron even during the early stage of the reduction from magnetite to wustite was established.

2.It is shown that both during nitrogen absorption in the range of $900{ }^{\circ} \mathrm{C}$ and by allotropic change of ferrite (alpha iron) to austenite phase (gamma iron) in weight percent absorbed causes volumetric expansion during nitriding.

3.By characteristics of the isothermal test, and during the cooling of the samples occurs the desorption of molecular gaseous nitrogen inside the reduced samples by the effect of thermodynamic equilibrium according to the Fe-N equilibrium diagram.

4.The effect of stresses caused by the desorption of nitrogen in the form of molecular gas is unstudied in the picture of mechanical stresses associated with the swelling mechanism of iron oxides.

5.There is a clear similarity in the trends of nitrogen adsorption and volume change curves.

\section{REFERENCES}

[1]O. Dam G. "The Influence of Nitrogen on the Swelling Mechanism of Iron Oxides During Reduction". Univ. of London. PhD Thesis 1983.

[2]J. Bogde. "Thermoelectric Power Measurements in Wustite. Univ. of Michigan”. 1976.

[3]O. Dam G. y J. Jeffes. "Model for the Assessment of Chemical Composition of reduced iron ores from single measurements. Ironmaking and Steelmaking”. Vol. 14, N'5. 1987

[4]M. Yang. "Nitriding-Fundamentals, modelling and process optimization". Tesis PhD. Worcester Polytech Institute. 2012

[5]EL Kasabgy. T and W-K. LU. "The Influence of Calcia and Magnesia in Wustite on the Kinetics of Metallization and Iron Whisker Formation”. Metallurgical 1980 American Society for Metals and the Metallurgical Society of AIME Volume 11b, pp. 410-414. 1980. 
[6]"Srikar Potnuru Studies nn the Physical Properties and Reduction Swelling Behavior of Fired Haematite Iton ore Pellets". MSc Thesis. Department of Metallurgical and Materials Engineering National Institute Of Technology, Rourkela May 2012

[7]R. Agarwal, S. Hembram. "To Study the Reduction and Swelling Behavior Iron Ore Pellets". BSc. Department of Metallurgical and Materials Engineering National Institute Of Technology, Rourkela May 2013

[8]C. Seaton., J. Foster. and J. Velasco. "Structural Changes Occurring during Reduction of Hematite and Magnetite Pellets Containing Coal Char". Transactions ISIJ, Vol. 23, 1983, pp.

[10]C. Bozco. "Interaction of Nitrogen with Iron Surfaces". Journal of Catalysis 49. pp16-41. 1977.

[11]L. Darken y R. Gurry. "Physical Chemistry of Metals". Mc Graw hIll . 1953.

[12]H. Weirdt and Z. Zwell, Trans. AIME. 229. 142. 1969

[13]J. Schulten. Trans. Soc. Faraday. 53, 1363, 1957.

[14]E. Barret y C. Wood. Bureau of Mines R-I 3229. 1934 